\title{
Immunocytochemical study of retinal diode laser photocoagulation in the rat
}

University

Department of

Ophthalmology,

Manchester University,

Manchester M13 9PT

P R S Richardson

D McLeod

School of Biological

Sciences, Manchester

University, Manchester

M13 9PT

M E Boulton

Department of

Ophthalmology,

Walton Hospital,

Liverpool L9 8XE3

J Duvall-Young

Correspondence to: Mr P Richardson, University

Department of

Ophthalmology and

Orthoptics, Royal

Hallamshire Hospital

Glossop Road,

Sheffield S10 2JT.

Accepted for publication

16 September 1996

\author{
P R S Richardson, M E Boulton, J Duvall-Young, D McLeod
}

\begin{abstract}
Aim-To determine the nature of the cellular infiltrate, alterations in cell adhesion molecules, and MHC II antigen expression in the rat retina following diode laser retinal photocoagulation.

Method-20 normal Lister rats underwent diode laser photocoagulation of the retina. Frozen sections from eyes enucleated at 0 , $1,5,13$, and 33 days post laser were examined for $T$ cells (R7.3), CD4 $T$ cells (W3/25), activated CD4 $T$ cells (OX-40), CD8 $T$ cells (OX-8), B cells (OX-33), and macrophages (OX-42), MHC II antigen (OX-6), and E-Selectin-1, VCAM-1, and ICAM-1.

Results-Retinal diode laser photocoagulation stimulated a wound healing response in the outer retina and choroid. The cellular infiltrate included macrophages and activated CD4 T cells at 13 and 33 days post laser. Glial cells in the inner plexiform and inner nuclear layers expressed MHC II antigen at 24 hours only. ICAM-1 antigen was induced in RPE cells and in Muller cells in the inner retina at all time intervals post laser and intense staining for ICAM-1 was present around intraretinal migrated cells at 13 and 33 days post laser. VCAM-1 antigen expression was induced in the choroidal vascular endothelium and RPE at 13 and 33 days after laser as was E-Selectin-1 antigen expression which was also evident focally at the external limiting membrane in association with migrated cells adjacent to the burn.
\end{abstract}

Conclusions-These results suggest that alterations in cell adhesion molecules may regulate the migration and activation of retinal pigment epithelium, macrophages and CD4 $\mathrm{T}$ cells at the outer blood-retinal barrier and choroid following diode laser photocoagulation of the normal Lister rat retina.

(Br F Ophthalmol 1996;80:1092-1098)

Retinal laser photocoagulation is generally successful in the treatment of retinal breaks, preventing retinal detachment by sealing the break against the flow of fluid vitreous across the neural retina. It is also effective in the management of vasoproliferative retinopathies including proliferative diabetic retinopathy, ischaemic central or branch retinal vein occlusion, and retinopathy of prematurity. However, the mechanisms by which scatter laser photo- coagulation induces regression of the new blood vessels are not fully understood.

Histological studies have demonstrated that argon laser photocoagulation of the retina primarily destroys the retinal pigment epithelium (RPE) and adjacent outer retina while the use of longer wavelengths (for example, red krypton and some diode lasers) results in additional destruction in the choroid. ${ }^{1-3}$ The first stage of the 'repair' process after laser is the arrival of subretinal macrophages and leucocytes in and below the wound area. ${ }^{3-10}$ Within 48 hours post laser, some RPE cells detach from Bruch's membrane and enter the wound site while others flatten, migrate along Bruch's membrane, and re-establish the outer blood-retinal barrier. ${ }^{10}$ Finally, glial cells proliferate and migrate into the wound site forming a cellular (nonfibrous) outer retinal scar within 21 days post laser. $^{58-10}$

Cell adhesion molecules and integrins are important sites of cell to cell and cell to matrix communication, mediating cell adhesion and signal transduction. ${ }^{11-13}$ During inflammation they allow leucocytes to interact with endothelial cells to regulate adherence and migration into the tissue ${ }^{13-18}$ and, together with MHC II antigens and modified proteins, are necessary for antigen presenting cells (APC) to activate $T$ cells. ${ }^{13}{ }^{19}$ Dendritic cells, macrophages, and B lymphocytes are most able to achieve $T$ cell activation and are often called professional APCs. The inflammatory cells release growth factors, lymphokines, and extracellular matrix components which modify the behaviour and function of various cells, including retinal capillary endothelial cells, RPE, and glial cells in vitro. ${ }^{20-26}$

Inflammatory retinal infiltration after laser photocoagulation has been poorly characterised and the role of inflammatory cells in the repair processes is unclear. The aim of this study was to determine the nature and temporal profile of the inflammatory cell infiltrate, together with changes in MHC II antigen and cell adhesion molecule expression, in the normal rat retina following laser photocoagulation.

\section{Materials and methods}

ANIMALS

Twenty adult Lister rats (200-250 g) were maintained ad libitum in a 12:12 hour light:dark cycle. No Home Office regulation regarding animal experimentation was transgressed. Lister rats were chosen because (a) they have a pigmented retina and choroid able 
Table 1 Details of the primary antibodies

\begin{tabular}{lllll}
\hline Antigen & Antibody & Dilution & Species & Source \\
\hline T cell (rat) & R7.3 & $1 / 100$ & Mouse & Serotec \\
CD4 T cell (rat) & W3/25 & $1 / 100$ & Mouse & Serotec \\
Activated CD4 T cell (rat) & OX-40 & Neat & Mouse & Serotec \\
CD8 T cell (rat) & OX-8 & $1 / 100$ & Mouse & Serotec \\
B cell (rat) & OX-33 & $1 / 100$ & Mouse & Serotec \\
Macrophage (rat) & OX-42 & $1 / 100$ & Mouse & Serotec \\
MHC II (rat) & OX-6 & $1 / 100$ & Mouse & Serotec \\
ICAM-1 (human) & & $1 / 75$ & Mouse & Cambridge Res \\
VCAM-1 (human) & & $1 / 75$ & Mouse & Cambridge Res \\
E-Selectin-1 (human) & & $1 / 75$ & Mouse & Cambridge Res \\
GFAP (bovine) & & $1 / 100$ & Rabbit & Dako \\
\hline
\end{tabular}

to take up the laser radiation, (b) the availability of well characterised antibodies to rat immunocompetent cells, and (c) the retina is vascularised by radial vessels on the surface of the internal limiting membrane with capillaries in the inner plexiform layer.

PHOTOCOAGULATION

Following halothane anaesthesia via a Boyle's machine, the rat's head was placed on a modified slit-lamp (Topcon SL $3 \mathrm{E}$, courtesy of Keeler, London) and 500-800 scattered applications of laser energy of spot size $50 \mu \mathrm{m}$, duration $50 \mathrm{~ms}$, and using power settings to create 'moderate' lesions, ${ }^{8}$ were undertaken in the retina of the right eye using a Microlase diode laser (Keeler, London). Four animals were sacrificed at each time interval $(0,1,5$,

Table 2 Number of infiltrating activated CD4 T lymphocytes (OX-40), macrophages (OX-42), and cells with MHC II antigens (OX-6) per 50 um spot size laser burn immediately post laser $(t=0)$ and at $1,5,13$, amd 33 days post laser

\begin{tabular}{|c|c|c|c|c|c|c|c|c|c|c|}
\hline & \multicolumn{5}{|c|}{ Within laser burn } & \multicolumn{5}{|c|}{ Around laser burn } \\
\hline & $t=0$ & 1 & 5 & 13 & 33 & $t=0$ & 1 & 5 & 13 & 33 \\
\hline \multicolumn{11}{|l|}{ OX-40: } \\
\hline Choroid & - & + & + & ++ & ++ & - & - & - & - & - \\
\hline RPE & - & + & + & ++ & + & - & - & - & - & - \\
\hline PR & - & - & - & + & - & - & - & - & - & - \\
\hline ELM & - & + & - & + & - & - & + & - & - & - \\
\hline ONL & - & - & - & - & - & - & - & - & - & - \\
\hline OPL & - & - & - & - & - & - & - & - & - & - \\
\hline INL & - & - & - & - & - & - & - & - & - & - \\
\hline IPL & - & - & - & - & - & - & - & - & - & 一 \\
\hline RGC & - & - & - & - & - & - & - & - & - & - \\
\hline NFL & - & - & - & - & - & - & - & - & - & - \\
\hline ILM & - & - & - & - & - & - & - & - & - & - \\
\hline \multicolumn{11}{|l|}{ OX-42: } \\
\hline Choroid & - & ++ & ++ & ++ & ++ & - & - & + & ++ & - \\
\hline PR & - & ++ & ++ & + & + & - & - & + & + & + \\
\hline ELM & - & ++ & ++ & ++ & + & - & - & ++ & + & + \\
\hline ONL & - & ++ & ++ & + & + & - & - & + & + & + \\
\hline OPL & - & + & + & - & + & - & - & - & + & + \\
\hline INL & - & + & - & - & - & - & - & - & + & + \\
\hline IPL & - & - & - & - & + & - & - & - & - & - \\
\hline RGC & - & - & - & - & - & - & - & - & - & - \\
\hline NFL & - & - & - & - & - & - & - & - & - & - \\
\hline \multirow{2}{*}{\multicolumn{11}{|c|}{ OX-6: }} \\
\hline & & & & & & & & & & \\
\hline Choroid & - & ++ & ++ & ++ & ++ & - & + & ++ & ++ & + \\
\hline Sub-RPE & - & ++ & ++ & ++ & + & - & + & ++ & + & + \\
\hline RPE & - & + & ++ & ++ & + & - & + & + & + & - \\
\hline PR & - & - & - & ++ & + & - & - & + & + & - \\
\hline ELM & - & - & - & + & + & - & - & + & - & - \\
\hline ONL & - & - & - & + & - & - & - & - & - & - \\
\hline OPL & - & - & - & - & - & - & - & - & - & - \\
\hline INL & - & + & - & + & + & - & + & - & - & - \\
\hline IPL & - & + & - & - & - & - & - & - & - & - \\
\hline RGC & - & - & - & - & - & - & - & - & - & - \\
\hline NFL & - & - & - & - & - & - & - & - & - & - \\
\hline ILM & - & - & - & - & - & - & - & - & - & - \\
\hline
\end{tabular}

Number of cells: $-=$ nil; $+=1$ to 3 cells; $++=4$ to 6 cells; $+++=>7$.

$\mathrm{PR}=$ photoreceptor layer; $\mathrm{ELM}=$ external limiting membrane; $\mathrm{ONL}=$ outer nuclear layer; $\mathrm{OPL}$ = outer plexiform layer; INL = inner nuclear layer; $\mathrm{IPL}=$ inner plexiform layer; $\mathrm{RGC}$ = retinal ganglion cell layer; NFL = nerve fibre layer; $\Pi \mathrm{LM}=$ inner limiting membrane.
13 , and 33 days) post laser and the eyes were immediately enucleated.

PREPARATION OF TISSUE

The enucleated eyes were embedded in OCT $(\mathrm{BDH})$, immersed in liquid nitrogen cooled isopropane for 6-7 minutes then stored at $-80^{\circ} \mathrm{C}$. Frozen sections ( 4 to $7 \mu \mathrm{m}$ thickness) were cut on a Reichart-Jung 7400 cryostat and collected on poly-l-lysine coated slides (Sigma), allowed to dry at room temperature, wrapped in Clingfilm, and stored at $-20^{\circ} \mathrm{C}$.

\section{ANTIBODIES}

The antibodies used in this study were obtained from a variety of suppliers (Table 1) and, where necessary, diluted in $0.01 \mathrm{M}$ TRIS buffered saline (TBS) pH 7.2 containing $1 \%$ bovine serum albumin. The R7.3 antibody recognises rat $T$ lymphocytes, the w3/25 antibody recognises the CD4 homologue in rat lymphocytes, ${ }^{27}$ and the OX-40 antibody identifies activated CD4 $\mathrm{T}$ cells. ${ }^{28}$ The antibodies for intercellular cell adhesion molecule-1 (ICAM1), vascular cell adhesion molecule-1 (VCAM1), and E-Selectin-1 were raised against human antigens but there is cross-reactivity with rat antigens. Rabbit antimouse IgG conjugated to biotin (Sigma) was used at a dilution of $1 / 200$ for the mouse primaries, and mouse antirabbit conjugated to biotin (Sigma) at a dilution of $1 / 150$ was used for the rabbit primary antibody.

\section{IMMUNOSTAINING}

The sections were fixed in acetone at $-20^{\circ} \mathrm{C}$ for 5 minutes, allowed to air dry then rinsed in $0.01 \mathrm{M}$ TBS $\mathrm{pH} 7.2$ for 5 minutes. Normal rabbit (or mouse) serum (1:10 Sigma) was used for 10 minutes to block non-specific binding before applying the primary antibodies for 1 hour. After three 5 minute washes in TBS the samples were exposed to the biotinylated secondary antibody for 30 minutes. The sections were washed three times for 5 minutes in TBS and incubated with an avidin-biotin alkaline phosphatase reaction complex (Dako) for 30 minutes. After further washing the tissues were made alkaline by immersing in 0.1 $M$ veronal acetate buffer $(\mathrm{pH} 9.2)$ for 5 minutes and antibody location was determined using a naphthol phosphate/fast red substrate mixture (Sigma) which, after 40 minutes, resulted in a red product. Endogenous alkaline phosphatase activity was blocked with levamisole. The washed slides were dried and mounted in UV adhesive (Loctite).

Positive control tissues were rat spleen and liver and negative controls were (i) omission of the primary antibody, and (ii) substitution of the primary antibody with an affinity purified mouse IgG at the same concentration as the primary antibody.

ASSESSMENT OF IMMUNOSTAINING

The number of cells as identified by RT.7, OX-40, OX-6, and OX-42 antibodies were counted in three or four $50 \mu \mathrm{m}$ laser burns in three or four different animals at each time 
Table 3 Staining intensity of choroid and retina for VCAM-1, ICAM-1, and E-Selectin-1 adhesion molecules immediately post laser $(t=0)$ and at $1,5,13$, and 33 days post laser

\begin{tabular}{|c|c|c|c|c|c|c|c|c|c|c|}
\hline & \multicolumn{5}{|c|}{ Within laser burn } & \multicolumn{5}{|c|}{ Around laser burn } \\
\hline & $t=0$ & 1 & 5 & 13 & 33 & $t=0$ & 1 & 5 & 13 & 33 \\
\hline \multicolumn{11}{|l|}{ VCAM-1: } \\
\hline Choriocapillaris & - & - & ++ & +++ & +++ & - & - & + & ++ & + \\
\hline RPE & - & - & ++ & ++ & ++ & - & - & - & - & - \\
\hline PR & - & - & - & - & - & - & - & - & - & - \\
\hline ELM & - & - & - & - & - & - & - & - & - & - \\
\hline ONL & - & - & - & - & - & 一 & - & - & - & - \\
\hline OPL & - & - & - & - & - & - & - & - & - & - \\
\hline INL & - & - & - & - & - & - & - & - & - & - \\
\hline IPL & - & - & - & - & - & - & - & - & - & - \\
\hline RGC & - & - & - & - & - & - & - & - & - & - \\
\hline NFL & - & - & - & - & - & - & - & - & - & - \\
\hline ILM & - & - & - & - & - & - & - & - & - & - \\
\hline \multicolumn{11}{|l|}{ ICAM-1: } \\
\hline Choriocapillaris & - & ++ & +++ & +++ & +++ & - & ++ & ++ & ++ & ++ \\
\hline RPE & - & +++ & +++ & +++ & +++ & - & ++ & ++ & ++ & ++ \\
\hline PR & - & - & - & - & - & - & - & - & - & - \\
\hline ELM & - & ++ & +++ & +++ & +++ & + & ++ & ++ & ++ & + \\
\hline ONL & - & - & ++ & ++ & ++ & - & - & + & + & - \\
\hline OPL & - & - & - & - & - & - & - & - & - & - \\
\hline INL & - & - & - & - & - & - & - & - & - & - \\
\hline IPL & - & - & - & - & - & - & - & - & - & - \\
\hline RGC & - & - & + & + & + & - & - & - & - & - \\
\hline NFL & - & - & - & - & - & - & - & - & - & - \\
\hline $\mathrm{ILM}$ & - & - & ++ & ++ & + & - & - & - & - & - \\
\hline \multicolumn{11}{|l|}{ E-Selectin-1: } \\
\hline Choriocapillaris & - & ++ & +++ & +++ & +++ & - & - & ++ & ++ & + \\
\hline RPE & - & ++ & +++ & +++ & +++ & - & - & ++ & ++ & + \\
\hline PR & - & - & - & - & - & - & - & - & - & - \\
\hline ELM & - & ++ & +++ & +++ & +++ & - & ++ & ++ & ++ & ++ \\
\hline ONL & - & ++ & ++ & ++ & +++ & - & ++ & ++ & ++ & + \\
\hline OPL & - & - & - & - & - & - & - & - & - & - \\
\hline $\mathrm{INL}$ & - & - & - & - & - & - & - & - & - & - \\
\hline IPL & - & - & - & - & - & - & - & - & - & - \\
\hline RGC & - & - & - & - & - & - & - & - & - & - \\
\hline NFL & - & - & - & - & - & - & - & - & - & - \\
\hline$\Pi \mathbf{M}$ & - & - & - & - & - & - & - & - & - & - \\
\hline
\end{tabular}

Intensity score: $-=$ no stain; $+=1 / 3$ contol tissue stain; $++=2 / 3$ control tissue stain; $+++=$ equal to control tissue stain.

$\mathrm{PR}=$ photoreceptor layer; ELM = external limiting membrane; ONL = outer nuclear layer; $\mathrm{OPL}$ = outer plexiform layer; $\mathbf{I N L}=$ inner nuclear layer; $\mathrm{IPL}=$ inner plexiform layer; $\mathbf{R G C}=$ retina ganglion cell layer; $\mathrm{NFL}=$ nerve fibre layer; $\Pi \mathrm{LM}=$ inner limiting membrane.

interval. Average counts of each cell type are presented in Table 2.

The intensity of the staining for ICAM-1, VCAM-1 and E-Selectin-1 in the lasered sections was compared with that of the control tissue and graded as one third, two thirds, or of equal intensity.

Rat spleen and liver were used as control tissues for the adhesion molecule antibodies and the specimens were viewed under an Olympus Vannox microscope and photographed with Ektachrome T160.

\section{Results}

GENERAL FEATURES

Within 24 hours of diode retinal photocoagulation necrosis of the RPE and swelling of the photoreceptor and outer plexiform layers was evident with macrophages in the photoreceptor layer and RPE layer (Fig 1g). At 5 and 13 days post laser RPE cells relined Bruch's membrane within the lesion and pigment bearing cells were present within the retina. By 33 days the outer retina was no longer swollen and a glial scar had formed. The intensity of the laser was insufficient to break Bruch's membrane and no choroidal new vessels (CNV) were detected histologically.

CELLULAR INFILTRATE

Immediately following laser $(T=0)$ no $T$ cells, $B$ cells, or macrophages were demonstrated in either lasered eyes or in non-lasered control eyes (Table 2). At 24 hours post laser OX-42+ macrophages were present in the choroid and outer retina within and around the burns (Fig 1a). The macrophages were initially more frequently identified beneath the laser burns in the choroid, by 13 days an increasing proportion was found intraretinally.

$\mathrm{T}$ cell lymphocytes identified by the R7.3 antibody (Fig 1d) were found in the choroid, photoreceptor layer, and at the external limiting membrane (ELM) at all time intervals other than $\mathrm{T}=0$, with greatest numbers at 24 hours. The anti-W3/25 antibody identified these as CD4 $\mathrm{T}$ cell lymphocytes and no CD8 (OX-8) T lymphocytes were seen. At 24 hours activated CD4 $\mathrm{T}$ cells (OX-40) were present beneath the RPE and in the choroid with increasing numbers at 13 and 33 days post laser (Table 2, Fig 1b). At no time were B cells (OX-33) detected in the choroid or retina.

\section{MHC II ANTIGEN EXPRESSION}

No retinal or choroidal cells expressed OX-6 MHC II antigens before laser. At 24 hours post laser choroidal endothelial cells around the laser burn and astrocytes in the inner nuclear layer around the laser burn stained for OX-6. The astrocytes and Muller cells stained with anti-GFAP antibodies at all intervals post laser (Fig 1e). Some RPE cells around the laser site expressed MHC II at 24 hours post laser and intraretinal pigmented cells were also identified by the OX- 6 antigen at the inner plexiform and inner nuclear layers.

By 5 days post laser MHC II antigen was present in the choroidal endothelium and in sub-RPE macrophages which were in greater numbers beneath the laser site. The RPE adjacent to the laser burn also stained for MHC II antigen, but the intensity rapidly decreased with increasing distance away from the burn. The intensity of OX-6 staining in the choroidal endothelium decreased by 33 days post laser.

Increasing numbers of choroidal OX-6 cells were present beneath the laser burn by 24 hours but decreased numbers were found by 33 days post laser with occasional OX-6 cells in the inner and outer plexiform layers at 33 days post laser (Fig 1c).

\section{CELL ADHESION ANTIGENS}

In the normal rat retina ICAM-1 antigen was present at the ELM and was not detected on RPE cells. At 1 and 5 days post laser there was increased staining for ICAM-1 in the RPE and choroidal vessels below the laser burn, in the ELM and in the outer nuclear layer (ONL) above the laser burn (Table 3). By 33 days ICAM-1 staining was present in the Muller fibres which surrounded the migrated intraretinal cells in the ONL (Fig 2a). There was also increased staining at 33 days for ICAM-1 above the laser burn at the ILM, in the RPE and the choriocapillaris around the laser and at sites away from the lesion.

Before and immediately after laser, E-Selectin-1 antigen could not be identified in the retina. The RPE and choriocapillaris around and beneath the laser burn stained for 

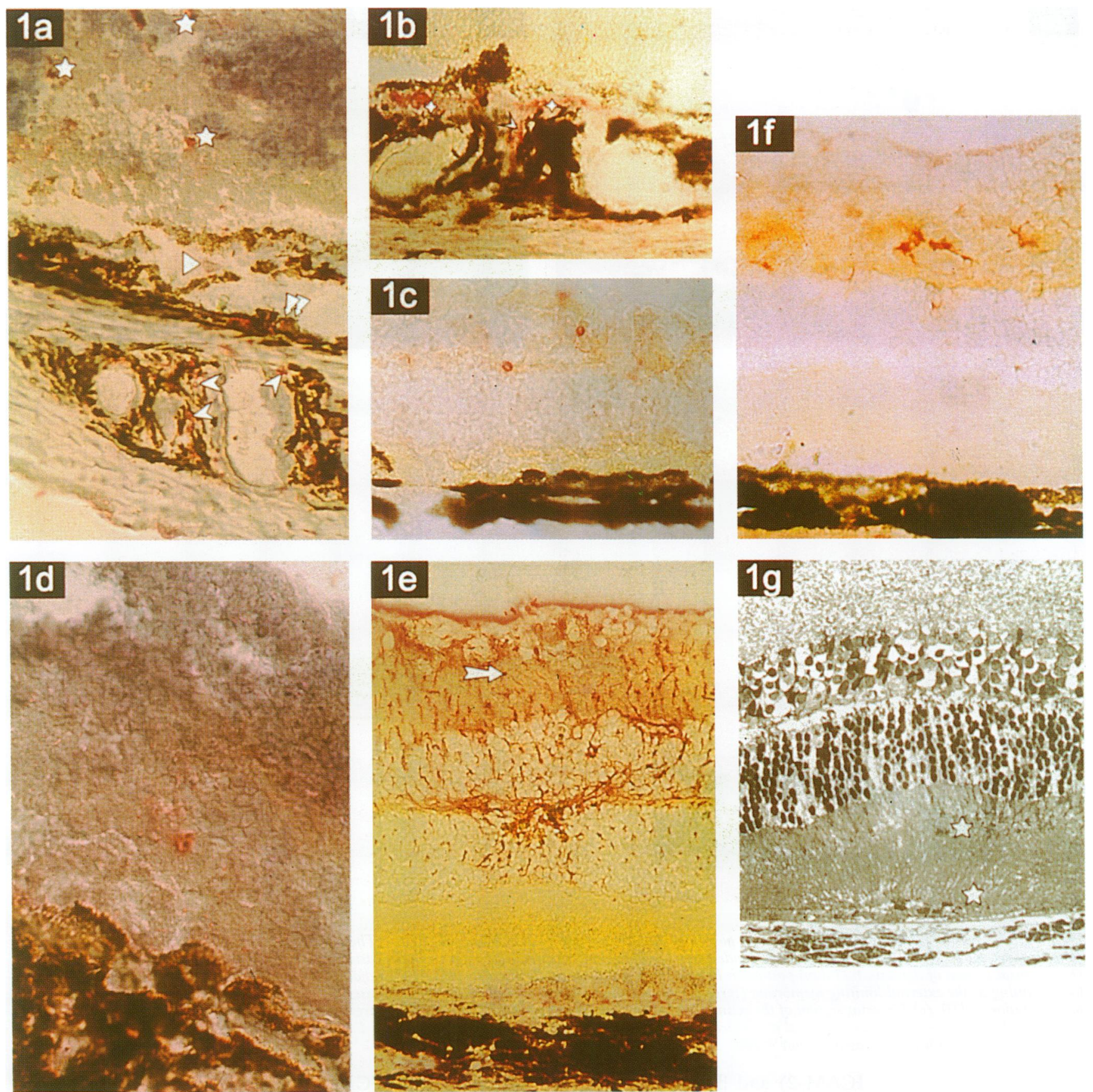

Figure 1 (a) Cryostat section of rat retina 1 day post laser immunostained for macrophages (OX-42, alkaline phosphatase-ABC, counterstained with haematoxylin). Macrophages are present in the choroid (double arrows), sub-RPE space (larger arrow), and intraretinally (asterisks). Numerous macrophages are present around the intrascleral posterior ciliary vessels (smaller arrows). Original magnification $\times 400$. (b) Cryostat section of rat retina at 33 days post laser. Activated CD4 T cells (OX-40,AP-ABC) in the deeper (arrow) and superficial (star) choroid. Original magnification $\times 600$. (c) Cryostat section showing MHC II (OX-6, AP-ABC) macrophages in the retina 33 days post laser. RPE and choroid adjacent to laser site do not stain for MHC II. Original magnification $\times 200$. (d) Cryostat section showing a T lymphocyte (R7.3, AP-ABC counterstained with haematoxylin) in the retina 24 hours post laser. Original magnification $\times 600$. (e) Cryostat section of rat retina showing Muller cell fibres (arrow) and astrocytes stain for glial fibrillary acidic protein (GFAP, AP-ABC) 13 days post laser. Original magnification $\times 400$. (f) Cryostat section of astrocytes in inner plexiform layer which stain for MHC II at 24 hours post laser (OX-6, $A P-A B C$ ). Original magnification $\times 400$. (g) Haematoxylin and eosin stain of rat retina at 13 days post laser. Macrophages and RPE cells are seen in the outer retina (star). Original magnification $\times 450$.

E-Selectin-1 at 1, 5, 13, and 33 days post laser. The ELM and Muller fibres above the laser burn had increased staining for E-Selectin-1 at 13 and 33 days but this decreased in intensity with increasing distance from the laser burn. Migrated, pigmented cells were in close proximity to sites of increased E-Selectin-1 at the level of the ELM (Fig 2b).

No retinal or choroidal cells expressed VCAM-1 antigens either immediately after or at 1 day post laser. VCAM-1 was detected in the choroidal vessels and RPE only at 5,13 , and 33 days post laser (Fig 2c); again the intensity decreased with increasing distance from the laser burn.

\section{Discussion}

Inflammation and immune surveillance require 'trafficking' of leucocytes between the blood stream, tissues, and lymphatics, a dynamic interaction usually regulated at the level of the vascular endothelium. ${ }^{11}{ }^{13}$ The integrin receptor consists of $\alpha$ and $\beta$ subunits and mediates cell-cell and cell-matrix interactions. ${ }^{29} \beta 1$ subfamilies interact with intercellular cell adhesion molecules-1 and -2 (ICAM-1, 

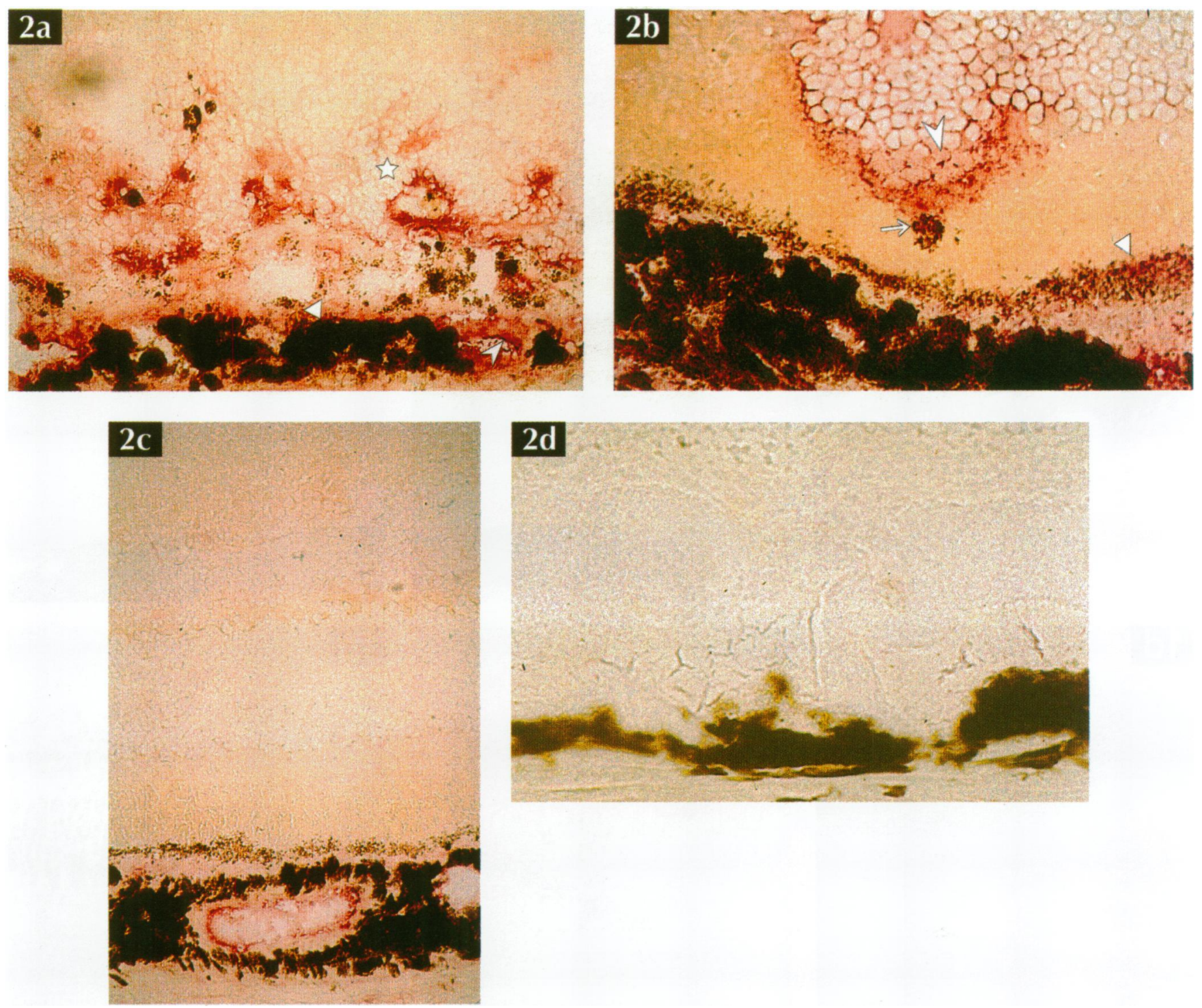

Figure 2(a) Cryostat section of rat retina 33 days post laser immunostained for ICAM-1 (AP-ABC). There is ICAM-1 on the choroidal endothelium (long arrow), RPE cells on Bruch's membrane (wide arrow) and around intraretinally migrated cells (asterisk). Original magnification $\times 200$.

(b) Cryostat section of the retina 33 days post laser. E-Selectin-1 is present on RPE cells (AP-ABC) adjacent to a laser burn (short arrow) with increased focal staining at the external limiting membrane (large arrow) opposite a migrated cell which also expresses E-Selectin-1 (long arrow). Original magnification $\times 450$. (c) Cryostat section of the retina at 33 days post laser. VCAM-1 ( $A P-A B C$ ) is present in the choroidal vascular endothelium, but not the RPE at a non-lasered site. Original magnification $\times 400$. (d) Cryostat section of the retina at 1 day post laser. Inappropriate antibody used as control $(A P-A B C)$. Original magnification $\times 200$.

ICAM-2) and $\beta 2$ with vascular cell adhesion molecule-1 (VCAM-1); both ICAM-1 and VCAM-1 are upregulated on endothelial cells by lymphokines. Once vascular endothelial cells are stimulated by lymphokines during inflammation, E-Selectin-1, with other selectins, is induced on the cell surface. Binding of ICAM-1 to the LFA-1 antigen on circulating leucocytes mediates transient tethering of leucocytes to the endothelium ${ }^{1416-17}$ and allows interaction with other factors which may be present on the endothelial cell wall as the leucocyte rolls along. ${ }^{16} \mathrm{IL}-8$ and other cytokines produced by endothelial cells and leucocytes during inflammation become immobilised on the endothelial cell wall and activate integrin receptors on tethered leucocytes resulting in strong adhesion ${ }^{11}$; if such factors are absent the leucocyte disengages. Migration into the tissue is under the influence of chemotactic gradients and further cell-matrix interactions to the site of inflammation. Normal, unstimulated RPE cells express ICAM-1 but not VCAM-1 or E-Selectin-1. ${ }^{3031}$ In human eyes with uveitis and following experimental autoimmune uveitis, these adhesion molecules are present on RPE cells and retinal capillary endothelial cells and may be induced by gamma interferon ( $\gamma$-IFN) and tumour necrosis factor- $\alpha$ (TNF- $\alpha) .{ }^{25}$ 30-34

The CD4 $\mathrm{T}$ cell will recognise only processed antigen if presented in combination with MHC II and other costimulatory molecules, including ICAM-1, on the surface of the antigen presenting cell (APC). ${ }^{13}{ }^{19}$ While RPE cells, retinal capillary endothelial cells, and glia have all been shown to express MHC II antigens, ${ }^{25}{ }^{35-37}$ their ability to activate CD4 T cells is variable and MHC II expression on 'non-professional' APCs may actually inhibit T cell function. ${ }^{37}$ MHC II dendritic cells at the RPE-choroid interface may act as APCs at the outer blood-retinal barrier. ${ }^{35}$

Our results demonstrate that, following retinal diode laser photocoagulation, macrophages and activated CD4 $\mathrm{T}$ lymphocytes are present 
in the wound during the formation of the chorioretinal adhesion. The nature of the inflammatory infiltrate may be of significance in the production of laser scars, since the behaviour of the retinal cells most often involved in the reparative process, the RPE cell and glial cells, can be modified by the released products of the activated inflammatory cells. $^{20-26}$ This may explain how variations of the power, duration, spot size, and wavelength of the laser, which determine the degree of the laser induced injury, ${ }^{8}$ modify the quality of the wound by differences in the extent and quality of the inflammatory response. From this immunocytochemical study it was not possible to determine if the activated CD4 T cells in the wound were involved in a specific antigen response after activation from an APC.

The laser induced inflammation is a focal wound healing response in which the inflammatory cells are no longer required once the wound has resolved. It differs in its aetiology and cellular infiltrate from immunologically mediated inflammation such as sympathetic ophthalmitis, experimental autoimmune uveitis, and proliferative vitreoretinopathy in which CD8 $\mathrm{T}$ cells and $\mathrm{B}$ cells are also present. ${ }^{25} 31343841$ In experimental autoimmune uveitis the CD4 activation is in two stages, ${ }^{42}$ the first by interaction with the CD3/TCR complex recognising the peptide/MHC complex. The second signal results from ICAM-1/ LFA-1 interaction which completes activation and allows clonal expansion. Monocyte macrophages are seen at all stages of the inflammation; CD4+ $\mathrm{T}$ cells predominate in early lesions and CD8+ $\mathrm{T}$ cells accumulate in later stages. B cells appear during the repair phase when the inflammation is subsiding. ${ }^{36} 39$

The retina is not a passive tissue into which the inflammatory cells enter during the wound healing process. Following the laser photocoagulation, the ability of choroidal vascular endothelial cells, RPE cells, and Muller cells to express ICAM-1, VCAM-1, and E-Selectin-1 cell surface antigens indicates that they are able to play an active role in inflammation and may function as regulators of leucocyte adhesion, activation, and migration. The expression of cell adhesion molecules in the inner retinal vascular endothelium was unchanged compared with non-lasered retina, and is consistent with the laser injury being confined to the outer retina.

Scattered retinal laser photocoagulation results in the regression of preretinal new vessel formation by, as yet, incompletely understood mechanisms. The presence of macrophages and CD4 T cells in the laser burn may initially appear paradoxical because of the stimulatory effects of many of the lymphokines and growth factors released. However, alterations in retinal and vitreal levels of growth factors, such as transforming growth factor $\beta$ have been described following retinal photocoagulation which may limit the action of the proinflammatory factors. ${ }^{43}$

This study provides some insight into the wound healing process in the normal rat retina following diode laser photocoagulation. Further studies are required to determine the precise role of the infiltrate in laser induced regression of neovascularisation.

The authors thank the Lasers for Life Trust, Liverpool, the Guide Dogs for the Blind, and Keeler (London) for their assistance in this study.

1 Wallow IH, Sponsel WE, Stevens TS. Clinicopathological correlation of diode laser burns in monkeys. Arch Ophthalmol 1991;109:648-53.

2 McHugh DA, Marshall J, fftyche TJ, Hamilton AM, Raven A. Macular photocoagulation of human retina with a diode laser: a comparative histopathological study. Lasers and Light in Ophthalmol 1990;3:11-28.

3 Marshall J, Bird AC. A comparative histopathological study of argon and krypton laser irradiations of the human retina. Brf Ophthalmol 1979;63:657-68.

4 Bresnick GH, Frisch GD, Powell JO, Landers MB, Holst GC, Dallas AG. Ocular effects of argon laser radiation. I Retinal damage threshold studies. Invest Ophthalmol 1970; 9:901-10.

5 Marshall J, Hamilton AM, Bird AC. Histopathology of ruby and argon laser lesions in monkey and human retina. $B r f$ Ophthalmol 1975; 59:610-30.

6 Pollack A, Korte GE. Repair of retinal pigment epithelium and its relationship with capillary endothelium after krypton laser photocoagulation. Invest Ophthalmol Vis $S c i$ 1990;31:890- 8

7 Perry DD, Reddick R, Risco JM. Choroidal microvascular repair after argon laser photocoagulation. Invest Ophthalmol Vis Sci 1984;25:1019-26.

8 Tso MOM, Wallow IHF, Elgin S. Experimental photocoagulation of the human retina. II Correlation of the coagulation of the human retina. II Correlation of the
physical, clinical and pathological data. Arch Ophthalmol physical, clinical and

9 Wallow IHF, Tso MOM, Elgin S. Experimental photocoagulation of the human retina. Arch Ophthalmol 1977;95: 1041-50.

10 Wallow IHF. Repair of the pigment epithelial barrier following photocoagulation. Arch Ophthalmol 1984;102:126-35.

11 Adams DH, Shaw S. Leucocyte-endothelial interactions and regulation of leucocyte migration. Lancet 1994;343: 831-6.

12 Humphries MJ. The molecular basis and specificity of integrin-ligand interactions. $\mathcal{F}$ Cell Sci 1990;97:585-92.

13 Springer TA. Adhesion receptors of the immune system. Nature 1990;346:425-34

14 Butcher EC. Cellular and molecular mechanisms that direct leukocyte traffic. Am F Pathol 1990;136:3-11.

15 Belvilacqua MP. Endothelial-leucocyte adhesion molecules. Annu Rev Imunol 1993;11:93-9.

16 Lawrence MB, Springer TA. Leucocytes roll on a selectin at physiological flow rates: distinction from and prerequesite for adhesion through integrins. Cell 1991;65:859-73.

17 Lasky LA. Selectins: interpreters of cell-specific carbohydrates information during inflammation. Science 1992;258: 964-9.

18 Shimizu Y, Newman W, Tanka Y, Shaw S. Lymphocyte interactions with endothelial cells. Immunol Today 1992;13: 106-12.

19 Swain SL. T cell subsets and the recognition of MHC class. Immunol Rev 1983;74:129-42.

20 Boulton ME, Patel B, Khaliq A, Moriarty P, Jarvis-Evans J, McLeod D. Modulators and milieu in preretinal neovascularization. Eye 1992;6:560-5

21 Boulton ME, Lane C, Singh A. Effects of vitreous from photocoagulated pig eyes on retinal microvascular cells in culture: a preliminary report. Curr Eye Res 1988;7:465-70.

22 De Vos AF, Hoekzema R, Kijlstra A. Cytokines and uveitis, a review. Curr Eye Res 1992;11:581-97.

23 Gilbert C, Hiscott P, Grierson I, McLeod D. Inflammation and the formation of epiretinal membranes. Eye 1988;2: $140-56$

24 el-Asar AM, Maimone D, Morse PH, Lascola C, Reder AT. Interferon-gamma and tumour necrosis factor induce expression of major histocompatability complex antigen on rat retinal astrocytes. $\mathrm{Br} \mathcal{F}$ Ophthalmol 1991;75:473-5.

25 Forrester JV, Liversidge J, Dua H S. Regulation of the local immune response by retinal cells. Curr Eye Res 1990;9 (suppl):183-91.

26 Sunderkotter C, Goebeler M, Schulze-Osthoff K, Bhardwaj R, Sorg C. Macrophage-derived angiogenesis factors. Pharmacol Ther 1991;51:195-216.

27 Clark SJ, Jeffries WA, Barclay AN, Gagnon J, Williams AF. Peptide and nucleotide sequences of rat CD4 (W3/25) antigen: evidence for derivation from a structure with four immunoglobulin-related domains. Proc Natl Acad Sci USA 1987;84:1649-53.

28 Paterson DJ, Jeffries WA, Green JR, Brandon MR, Corthesy $\mathrm{P}$, Pulavec M, et al. Antigens of activated rat $\mathrm{T}$ lymphocytes including a molecule of $50.000 \mathrm{M}$ (r) detected only on CD4 positive T blasts. Mol Immunol 1987;24:1281-90.

29 Elner SG, Elner VM. The integrin superfamily and the eye. Invest Ophthalmol Vis Sci 1996;37:696-701.

30 Duguid IGM, Boyd AW, Mandel TE. The expresion of adhesion molecules in the human retina and choroid. Aust NZ F Ophthalmol 1991;19:309-16.

31 Kuppner MC, Liversidge J, McKillop-Smith S, Lumsden L, Forrester JV. Adhesion molecule expression in acute and fibrotic sympathetic ophthalmia. Curr Eye Res 1993;12: 923-34. 
32 Liversidge J, Sewell HF, Forrester JV. Interactions between lymphocytes and cells of the blood-retina barrier: mechanisms of T lymphocyte adhesion to human retinal capillary nisms of T lymphocyte adhesion to human retinal cap

33 Whitcup SM, Chan C-C, Li Q Nussenblat RB. Expression of cell adhesion molecules in posterior uveitis. Arch Ophthalmol 1992;110:662-6.

34 Forrester JV, Liversidge JM, Dua HS, Dick A, Harper F McMenamin PG. Experimental autoimmune uveitis: model system for immunointervention. Curr Eye Res 1992; 11:33-40.

35 Forrester JV, McMenamin PG, Holthouse I, Lumsden I Liversidge $J$. Localization and characterization of major histocompatibility complex class II-positive cells in the posterior segment of the eye: implications for induction of posterior segment of the eye: implications for induction of
autoimmune uveoretinitis. Invest Ophthalmol Vis Sci autoimmune uvi:

36 Chan C-C, Hooks J, Nussenblatt RB, Detrick B. Expression of Ia antigen on retinal pigment epithelium in experimental autoimmine uveitis. Curr Eye Res 1986;5:325.

37 Caspi RR, Roberge RG, Nussenblatt RB. Organ-resident, non-lymphoid cells suppress proliferation of autoimmune T-helper lymphocytes. Science 1987;237:1029-32.
38 Baudouin C, Brignole F, Bayle J, Fredj-Reygrobeller D, Lapalus P, Gastaud P. Class II histocompatability antigen Lapalus P, Gastaud P. Class II histocompatability antigen expression by cellular components of vitreous and subthalmol Vis Sci 1991;32:2065-72.

39 Liversedge J, Forrester JV. Experimental autoimmune uveitis: immunophenotypic analysis of inflammatory cells in chorio-retinal lesions. Curr Eye Res 1988;7: $1231-41$.

40 Peterson JM, Barbul A, Breslin RJ. Significance of T lymphocytes in wound healing. Surgery 1987;102:300-5.

1 Lightman S, Chan C-C. Immunopathology of ocular inflammatory disorders. London. Kluwer Academic, 1989.

42 Schwartz RH. A cell culture model for T lymphocyte clonal anergy. Science 1990;248:1349-56.

43 Boulton ME, Xiao M, Khaliq A, Moriarty P, Cranley J, McLeod D. Changes in growth factor expression in pig eyes following scatter laser photocoagulation. Invest Ophthalmol Vis Sci 1995;36:s95.

44 Matsumoto $M$, Yoshimura N, Honda Y. Increased production of TGF- $\beta$ from cultured human RPE cells by photocoagulation. Invest Ophthalmol Vis Sci 1994;35:4245- 